\title{
E-Tandem Learning in CCU Class: An Attempt to 'Bring' Intercultural Communication in to the Classroom
}

\author{
Girindra Putri Dewi Saraswati ${ }^{1}$, Izzati Gemi Seinsiani ${ }^{2}$, Anjarnanda Ihda Sujarwanto ${ }^{3}$ \\ \{girindraputrids@mail.unnes.ac.id ${ }^{1}$, izzatiseinsiani@ mail.unnes.ac.id ${ }^{2}$, anjarnanda77@gmail.com ${ }^{3}$ \} \\ ${ }^{1,2,3}$ Universitas Negeri Semarang, Indonesia
}

\begin{abstract}
This study aims at finding out to what extent the implementation of E-Tandem Learning in Cross-Cultural Understanding (CCU) class can become one alternative in bringing the Intercultural Communication experience to the students in the classroom. ETandem Learning was given to 23 English Department students of UNNES Indonesia by asking them to make online contact with 20 students of SUNY at Albany for three weeks. At the end of the session, students created a report on the activity, filled out questionnaires, and was interviewed by the researchers. The study is presented in qualitative research design by using questionnaires and interviews as the data collection instruments. Results showed three claims towards the implemented activity. First, E-Tandem learning promotes students' awareness of the Importance of CCU in English Communication. Second, E-Tandem learning forces students to be confident with their English. Third, E-Tandem learning activity can help students to understand the concept of CCU.
\end{abstract}

Keywords: E-Tandem Learning; CCU; intercultural communication

\section{INTRODUCTION}

Since the notion of English as a Lingua Franca is spread out, and world citizen well knows the conception of English used as an international language for communication, culture has been important to be discussed. The success of foreign speakers to communicate in English is when the communication goal is achieved when there are different cultures involved and create differences in interpretation and expectation [1]. Learning English is not only understood by learning the grammar or the pronunciation of the language, but more to learn other cultures. Before, when English was known to be the native language of the United Kingdom or the United States, then, people were eager to learn about how British people or Americans behave and communicate, some people even learned the accents of the native English users. The paradigm shifts. In these years, English is acknowledged as one of the International languages for communication. Not only to be able to use and be fluent in using English as a language, but speakers also have to deliver and receive information to achieve the communication goal without causing misunderstanding caused by differences of norms, cultures, and behaviors of the speakers. This way, a speaker is labeled as to have the Intercultural Communication competence [2]. On the other hand, it can be inferred that what necessary for the English users is not only to master the language but also to bridge differences in the culture of other English users.

Earlier studies had learned about cultures in English teaching [3], [4], [5]. Rappel [3] mentioned that using an Intercultural approach as the basic instruction in the English classroom 
could give input to students on how culture is related to the English that they learn. Further, it was mentioned by Rappel that activities to promote intercultural understanding, such as observation, discussion, and English conversation dialogue based on students' experience in real life. Students' knowledge of other's cultures could push the students to explore their understandings of cultures and insert it as one of the material to practice communicating in their English classroom. In addition to Rappel is Scollon \& Scollon [4], they created a methodology of a teaching model, comprising: ideology which is sets of question used for teachers to reflect their teaching material to the culture and stereotypes which might be had by their students, socialization which is sets of questions to be used by teachers to dig up some crucial aspects of the social life of their students, discourse analysis which allows teachers to consider some subcultures that might have formed the understanding of cultures of the students, and the politeness system that is sets of questions used by teachers to formulate ways to find out the students' sociolinguistics background. The result of this study is a set of Lesson Plan of English that inserts and integrated the knowledge of Intercultural understanding in it. Besides the teaching instructions and techniques as well as teaching methodology, the teaching material in the form of students' textbooks had also been researched by Ho [5], who found that activities in the Vietnamese university textbook were still limited only on the topics related to cultures of the target language. In contrast, there was a lack of information about the local culture of the students themselves.

On the other hand, to explore and achieve Intercultural competence, one needs to understand his own local culture and master the target culture. Therefore, that cultural understanding can be formed and lead to an Intercultural competence. Thus, Ho adds four more activities in the textbook to open more possibilities for culture understanding, i.e., exploring self, noticing/ observation, cultural exploration, comparisons and reflections, and mediation between cultures.

Considering the need to promote cultures for students learning English, the English Department of Universitas Negeri Semarang also acknowledge the necessity of teaching cultures to students by giving students one specific subject to learn, namely Cross-Cultural Understanding (CCU). In the CCU class, they are taught to understand differences in culture and to bridge the gaps to avoid misunderstanding. In the academic year 2018/2019, researchers decide to implement E-Tandem Learning in CCU teaching for the students to have an authentic experience of English communication with speakers from different cultural backgrounds. As many as 23 UNNES students who took CCU class were given a chance to have distance communication with 20 students from State University of New York at Albany (SUNY Albany). Considering the distance between the participants, therefore, students used social media and/or other online communication tools through the internet to be in contact with SUNY at Albany's students. The method is labeled as E-Tandem Learning. This study will focus on studying the perception of UNNES students upon the newly implemented method given in the CCU Class. The students' perception towards the new teaching method implemented will provide a picture for the researchers about the advantages/disadvantages of the original method implemented, especially, and to further give recommendations if the method is well applied, and vice versa if the method is not suitable for the students.

Intercultural Communication in English Teaching can be understood as a view that English learners who learn English as a Foreign Language need to employ. It is an insight into the learners' native culture and the target language culture [6]. Besides, Hill refers to a more cognitive aspect on a cultural understanding, which supposed to comprise knowledge about one's native culture and other cultures of languages that one learns [7]. Among the languages are similarities and differences in cultures. In other words, the learners of English should also be equipped with the knowledge of the learners' own cultures and English culture for them to 
be able to negotiate and understand the meaning of intercultural communication. It is not only about language being communicated, but also the secondary meaning behind one's way to communicate based on habits and norms. Thus, the cognitive aspects allow English learners to understand direct and indirect ways of communication so that misunderstanding can be avoided [8]. This way, we can refer to Intercultural Understanding.

Furthermore, in terms of introducing the Intercultural Understanding, it was found that one effective technique that can be implemented is through activities of discussion or generating interpretation involving intercultural knowledge and understanding [9]. These activities can be done in the classroom with classmates. Still, for Intercultural teaching, students will also need inputs from other cultures for the lesson of Cross-Cultural Understanding to be more authentic. It is considered more trustworthy since the learning activity will allow the students to communicate directly with their Tandem friends online [10]. It will bring more experiences for the students instead of watching some sample clips from videos.

Still based on Cziko, E-Tandem Learning is an approach in teaching English in the $21^{\text {st }}$ century. It is a teaching method that allows collaboration between two different students from two countries to be connected and learn from each other by using technology to connect them. It was originated from the term 'Tandem' which means collaboration in teaching. We add 'E' to emphasize the use of email and other social media as the communication tool in the implementation. Byram and Feng used the term to refer to a method that can be used as an alternative to increase the performance of language training and to improve one's understanding of Intercultural knowledge [11].

The E-Tandem Learning was also implemented in UNNES' English Department CCU Class. Therefore, since it is the method to be implemented, researchers are going to find out to what extent the implementation of E-Tandem Learning in Cross-Cultural Understanding (CCU) class can become one alternative in bringing the Intercultural Communication experience to the students in the classroom. Indirectly, the student's perception will become the source of this study. Students' perception is considered essential to know how students perceive the materials given to them. Therefore, teachers can understand what type of teaching technique suitable for teaching students [12], or in this case, whether the method or technique of teaching implemented has been ideal with the students' needs. Jenna Tudor et al. researched perceptions and their influences on approaches to learning for their mechanical engineer students. The results show that the students' perception of what subjects and behaviors are important for the students. Students have their expectations, and by researching students' perceptions, we can generate ideas on whether the lesson being taught has met the students' expectations. Another research on perception was done by Irwin et al. They found that Facebook as a new phenomenon in technology could become one platform that may facilitate learning at the university. The students' perception gives those data that using Facebook is the potential for learning [13].

Earlier studies had shown about several studies conducted the method of teaching intercultural elements in English classes, the textbook, and even the perceptions of students on specific approaches or techniques in teaching and how perception is linked to the teaching process. This study will bring new insight into the intercultural research on ELT by investigating E-Tandem Learning as a new method in ELT. The E-Tandem Learning method, which was implemented for fourth-semester students at the English Department of UNNES, was a new method in CCU Class. Therefore, getting the data on students' perception of the new method is considered necessary. The data gathered will give the researchers an understanding of how students perceive the new method and whether it is worthy of being implemented or not.

The E-Tandem learning activities mentioned were conducted by 20 students from SUNY Albany and 23 students of UNNES for three weeks. They are contacted with each other and try 
to find some information about life in each different environment. They discuss differences of cultures in their neighborhoods and countries and how they cope with it. Specifically, for students of UNNES, they do not only have the idea of living in the U.S. environment, but also the way the students and SUNY at Albany's students communicate with each other is the intercultural communication itself. On the other hand, the activity allows students to practice bridging differences of cultures in English communication between two speakers from different cultural and country background.

Therefore, the research question derived for this study is to what extent the implementation of E-Tandem Learning in Cross-Cultural Understanding (CCU) class can become one alternative in bringing the Intercultural Communication experience to the students in the classroom?

\section{METHOD}

The research was conducted by employing qualitative as the study method. By using the qualitative method as the study design, we wanted to use this study to present to what extent the implementation of E-Tandem Learning in Cross-Cultural Understanding (CCU) class can become one alternative in bringing the Intercultural Communication experience to the students in the classroom. Using a qualitative method, one would be able to observe people in their environment, the interaction, and create interpretation towards it [14].

There are 23 students acted as the object of study. The research design was a case study that aims to obtain detailed results and relate to a specific case by linking the case to the theory [15]. By doing a case study, the researchers studied the implementation of E-Tandem Learning in CCU Class of English Department, Universitas Negeri Semarang in the academic year 2018/2019. The techniques implemented in the study were open-ended questionnaires and semistructured interviews.

First of all, students were given theories of CCU in 3 meetings by their lecturer. Then, after three sessions, students were assigned a work that requires them to be in contact with their ETandem buddy from SUNY at Albany through social media or video call. This work allows three weeks for the students to communicate with their E-Tandem buddy to talk about culture and their interpersonal life. After three meetings, the students were given an open-ended questionnaire and were interviewed based on the answers of their questionnaires for the researchers to obtain more precious data. As it has been mentioned by earlier researchers, the open-ended format allowed interviewees and participants to elaborate on issues raised in an informative manner [16].

\section{RESULT AND DISCUSSION}

After obtaining answers from students from both questionnaires and interviews, researchers could summarize and group the responses into three claims. They are E-Tandem learning promotes students' awareness of the Importance of CCU in English Communication, Intercultural Communication in English, E-Tandem learning forces students to be confident with their own English, and E-Tandem Learning activity can help students to understand the concept of Cross-Cultural Understanding (CCU).

\section{E-TANDEM LEARNING PROMOTES STUDENTS' AWARENESS ON THE IMPORTANCE OF CCU IN ENGLISH COMMUNICATION}

Intercultural Communication in English as part of Cross-Cultural Communication comprises a broad scope of understanding. It is not only about languages that they use, but also about 
gestures, intention, behavior, etc. Results of the questionnaires and interviews show that at the end of the session of E-Tandem Learning, students understand that sometimes the choice of words can be understood differently by their E-Tandem buddy. While for some students experiencing video call or audio call also mentioned that English is not like what they see on TV or what they learn during listening class. Students understand that English has many versions of accent, dialect, and even though it is rather hard, but they can understand their study buddy.

\section{Student \#5 mentioned:}

"She (her study buddy) use the word that when I translate into my language, the meaning will be ambiguous."

Student \#5 believes that some misunderstandings occurred though he and his mate share the same language, English. However, the way they understand the situation or the way they use the languages sometimes brings misunderstanding.

Student \#13 mentioned:

"Yes. At first, I always called him Mr. Andy. I did it because I wanted to show my respect towards him, who was older than me. But then he didn't like it. He told me that I just need to called him Andy without Mr. Then he also said, if I want to show respect, it was better to called someone with their title for example Dr."

Another expert from student \#13 shows that addressing systems also part of learning in ETandem activity. According to student \#13, addressing the system which was taught during classes was not as easy as it sounds when it is implemented in real communication with foreigners using English. He knows and understands that address someone with the first name in Western Countries is acceptable, but he cannot avoid his feeling of guilt referring to someone older without any salutation. However, he finds out eventually that the person is not comfortable being called by using "Mr." or "mister". In the end, to bridge the misunderstanding, he follows the instruction from his opponent speaker to call him by the first name without salutation.

\section{Student \#12 mentioned}

"Yes, I think having foreigners to be my sharing buddy can increase my understanding towards differences in culture because I got the chance to see thing from different points of view, widen my perspectives, and improved my cultural awareness."

Some students answer in general way as it was done by student \#12. In general, having ETandem buddy makes them aware that culture is various. The misunderstanding might happen because the same term or word for different people from a different country can mean differently. It might also bring a different point of view for the students from the way they see the phenomenon. For example, it was mentioned by student \#12; for him, he understands the 
concept of racism in theory and realizes that he should not be racist. However, in his environment, he believes that racism is just a concept that, in real life, all neighbors and friends of his were considered polite and neutral. However, during his talk with his E-Tandem buddy, he believes that another part of a more multicultural country or place, racism is an issue that will cause friction in society.

\section{E-TANDEM LEARNING FORCES STUDENTS TO BE CONFIDENT WITH THEIR ENGLISH}

In general, most students feel confident in using their English because they are forced to do so unless they will not complete their assignments at first. However, after knowing their ETandem buddy, their confidence increases because they believe the communication goal is achieved that their E-Tandem buddy can understand their English. It shows form the way their buddy responds to them. When it satisfies them, it means that their communication is connected.

Student \#3 mentioned:

No, I didn't have any misunderstandings with my buddy, our communication went very well.

Student \#11 mentioned:

No. I didn't get any misunderstanding. My partner answered my questions clearly and on point.

Most students feel confident with their English as their E-Tandem buddy can understand them (see the example from student \#3 and \#11). Student \#3 and \#11 feels appropriateness from the responses he receives while having a conversation. From the feedback, the student feels confident that his buddy understands him that at the same time also reflects that his English is good and acceptable in international communication that makes him confident to use it.

Though some students feel happy that their E-Tandem buddy understands their English, some others do not feel confident about their English and seem to blame themselves for misunderstanding that might be happened.

Student \#12 mentioned:

"Yes, I think the misunderstanding came from me because of my English language skill. So, when Mrs. Anne asked me about something, it confused me whether she asked about A or B. Therefore, I asked Mrs. Anne for confirmation by repeating the question in my own language."

The opinion from Student \#12 obtained from his open-ended questionnaire and supported by the interview results shows that he took the misunderstandings which happened during the interview as his mistakes. He is fully aware that he is coming from Indonesia, which is an EFL country, and that English is not even our second language. Therefore, he thinks that 
misunderstanding might occur because he could not understand the statement delivered by his E-Tandem buddy.

However, he found a way to overcome misunderstanding by repeating his E-Tandem buddy's statement for confirmation. In his perspective, this way is more acceptable and polite rather than keep asking his E-Tandem buddy to repeat her statement. Another example of similar to the previous expert was coming from student \#6.

Student \#6 mentioned:

"Yes, I did. There are a lot of misunderstandings going on between me and Beverly. It's maybe because my language is not that fluent or sounding common to Beverly's that she cannot fully understand what I meant. However, the biggest misunderstanding goes to me for I was careless. The document I sent to Beverly was totally the one which I had answered on a half. And the saddest part is, I realized it weeks after I sent it. And I was wondering why didn't she asked me that the document was partially answered. I regret my inconvenience after all. It is okay for the data, because I think she got my data from my partner, Astrid, because we surprisingly come from the same region. But eventually, I apologized and resend the complete answer to her. She said it was alright."

From student \#6, the student feels not confidence and thinks that he might have caused misunderstanding because he could not meet the goal of communication. It was told that at one point when his E-Tandem buddy needs some documents from him, he sent the different one because he did not understand. From that, he feels that his English hasn't been able to be accepted by foreigners from a different country.

\section{E-TANDEM LEARNING ACTIVITY CAN HELP STUDENTS TO UNDERSTAND THE CONCEPT OF CROSS-CULTURAL UNDERSTANDING (CCU)}

Two other points mentioned above are about students' awareness of CCU promoted through E-Tandem Learning and students' confidence in English after the implementation of E-Tandem learning. The third part of the discussion is about the conformity of E-Tandem learning to be implemented in the $\mathrm{CCU}$ class to obtain understanding receives good comments from all students. They believe that having other speakers to talk can increase their understanding of the conception of CCU in real English communication. As mentioned by some students:

Student \#11 mentioned:

"Yes, I do think having foreigners to be my sharing buddy can increase my understanding towards differences in culture. Because we come from a different country which one must have various cultures. By that, it solidifies me to respect differences, to understand things from different perspective without even forgetting our own culture. Additionally, knowing another's culture means giving very wide and vast knowledge about cultures and one's country.", 
Student \#23 mentioned:

"Yes. I think having foreigners to be our sharing buddy can increase your understanding of the culture differences because the more people we know the more culture we learn."

Student \#1 mentioned:

Yes I think it is important to have the real experience and sharing the idea with someone who had experienced it before so we can get more knowledge rather than just learn the theory in the class.

From the activity the students do, they think they have more experiences though they are not living in other countries. By having more experiences here are, i.e., differences in culture and increasing knowledge about different cultures. As student \#1 mentioned, practically doing the communication with foreigners, bring him to the stage where he could be more understanding. The indirect experience he got from E-Tandem learning activity was more real and practical rather than only learning about the theory in the classroom. Some misunderstandings that occurred and some mistakes are done by the students were not merely the fault and errors of the students but new experiences that they learn in E-Tandem activity as an attempt to 'bring' intercultural communication into the classroom.

Generally, from what we had collected during the study, it was found that the use of ETandem learning has supported CCU learning in the classroom. As Byram and Feng mentioned earlier, E-Tandem learning can be used as an alternative to increase the performance of language training and to improve one's understanding of Intercultural knowledge. Particularly in Indonesia, where the society is majority Indonesian, and immigrants are not common to be seen, Bahasa Indonesia still becomes one main language as a means of communication between its citizens. English is a foreign language that will only be used when one needs to communicate with a foreigner who happens visiting Indonesia and has business with him. Therefore, E-Tandem learning is a solution to the need for international exposure in CCU class.

The need for international exposure in intercultural learning was earlier mentioned by Gregersen-Hermans [17], who believes that the impact of exposure to diversity in the international university environment may bring influences in the increase of Intercultural Competence of students. As also mentioned by students in the last subsection, the activity allows them to understand other cultures as it happened to have many dimensions that seemed simple in theory yet tricky in real communication. Even students \#12 in the previous subsection feels the failure of communication since he failed in understanding the meaning of utterance mentioned by his E-Tandem buddy. As previously mentioned by Suneetha, Y., \& G. M. Sundaravalli, only the cognitive aspect will allow English learners to understand direct and indirect ways of communication so that misunderstanding can be avoided. E-Tandem learning, indeed, promotes the chance for students to be closer to real intercultural communication. 


\section{CONCLUSION}

This paper aims to show the readers to what extent the implementation of E-Tandem Learning in Cross-Cultural Understanding (CCU) class can become one alternative in bringing the Intercultural Communication experience to the students in the classroom. The research was conducted by giving 23 students of UNNES an open-ended questionnaire and interview regarding the implementation of ETandem learning that the students had experienced by contacting students of SUNY at Albany for three weeks to discuss culture and to have some interpersonal communication. Results show that E-Tandem learning may promote international exposure to students and result in the possibility for students to learn the conception of CCU during the activity. E-Tandem learning activity itself is beneficial for teaching $\mathrm{CCU}$ in the classroom as it is proven to be useful in some extents, as follows: first, E-Tandem learning promotes students' awareness of the Importance of CCU in English Communication. Second, ETandem learning forces students to be confident with their English. Third, E-Tandem learning activity can help students to understand the concept of CCU.

\section{References}

[1] Lustig, M. W., and J. Koester, "Cultural biases and intercultural communication," Among US: Essays on identity, belonging, and intercultural competence, vol. 2, pp. 157-173, 2006.

[2] Byram, M, " Twenty-five years on-from cultural studies to intercultural citizenship," Language, culture and curriculum, vol. 23, no.3, pp. 209-225, 2014.

[3] Rappel, L, "An analysis and interpretation of intercultural approaches to English language teaching," Journal of Integrated Studies, vol. 1, no.2, 2011.

[4] Scollon, R., \& S. Scollon, "Somatic communication: How useful is "orality" for the characterization of speech events and cultures," Aspects of oral communication, pp. 1929, 1995.

[5] Ho, S.T.K., "Addressing culture in EFL classroom: the challenge of shifting from a traditional to an intercultural stance," Electronic Journal of Foreign Language Teaching, vol. 6, no.1, pp. 63-76, 2009.

[6] Kramsch, C., Language and culture, Oxford: Oxford University Press, 1998.

[7] Hill, I., "Student types, school types and their combined influence on the development of intercultural understanding," Student types, school types and their combined influence on the development of intercultural understanding, Vol. 5, No. 1, pp.5-33, 2006.

[8] Suneetha, Y., \& G. M. Sundaravalli, Incorporating Cross-cultural Communication in ELT: A Pedagogical Approach, Singapore: National University of Singapore, 2011.

[9] Troncoso, C.R., "The effects of language materials on the development of intercultural competence," in B. Tomlinson and H. Masuhara (Eds.) Research for materials development in language learning: evidence for best practice, London: Continuum, pp. 83-102, 2010.

[10] Cziko, G. A. "Electronic tandem language learning (eTandem): A third approach to second language learning for the 21 st century," Calico Journal, Vol. 22, No. 1, pp. 25 39, 2004.

[11] Byram, M. \& A. Feng, "Culture and language learning: Teaching, research and scholarship,” Language teaching, Vol. 37, No. 3, pp. 149-168.

[12] Tudor, J., et al., "Perceptions and their influences on approaches to learning." engineering education, Vol. 5, No.2, pp. 69-79, 2010. 
[13] Irwin, C, et al., "Students' perceptions of using Facebook as an interactive learning resource at university," Australasian Journal of Educational Technology, Vol. 28, No. 7, pp. 1221-1232, 2012.

[14] Nasution, S., Metode Penelitian Naturalistik Kualitatif. Bandung: Tarsito, 1996.

[15] Bryman, A. Social research methods. Oxford: Oxford University Press, 2012.

[16] Dörnyei, Z., Research methods in applied linguistics. Oxford: Oxford University Press, 2007.

[17] Gregersen-Hermans, J. "The impact of exposure to diversity in the international university environment and the development of intercultural competence in students." The European higher education area. Springer, Cham, 2015. pp. 73-92. 